\title{
Exertion in Kangoo Jumps Aerobic: Evaluation and Interpretation Using Spectroscopic Technique Determinations
}

\author{
Cristina Popa, ${ }^{1}$ Mihai Patachia, ${ }^{1}$ Stefan Banita, ${ }^{1,2}$ and Dan Constantin Dumitras ${ }^{1,2}$ \\ ${ }^{1}$ National Institute for Laser, Plasma and Radiation Physics, Bucharest-Magurele, 409 Atomistilor Street, \\ P.O. Box MG-36, 077125 Bucharest, Romania \\ ${ }^{2}$ Faculty of Applied Sciences, University Politehnica of Bucharest, 060042 Bucharest, Romania \\ Correspondence should be addressed to Cristina Popa; cristina.achim@inflpr.ro
}

Received 29 May 2013; Revised 11 July 2013; Accepted 1 August 2013

Academic Editor: Ekaterina Borisova

Copyright (C) 2013 Cristina Popa et al. This is an open access article distributed under the Creative Commons Attribution License, which permits unrestricted use, distribution, and reproduction in any medium, provided the original work is properly cited.

\begin{abstract}
Laser photoacoustic spectroscopy (LPAS) is growing quickly in its applications to real world problems-one of the problems is to prevent obesity-being a candidate technology for breath analysis applications. The ongoing paper is aiming to investigate the evaluation of oxidative stress in womens practicing Kangoo Jumps $(\mathrm{KJ})$ aerobics. Because it is not possible to directly measure free radicals in the body, we approach that by measuring the by-products (breath ethylene) that result from free radical reactions. We found out that the mixture of exhaled breath in women's after the KJ exercises contains low concentration of ethylene compared to the exhaled breath of the women before the start of exercise program. This result can add valuable information to the contribution to reduce the generation of prooxidants during and after KJ aerobics.
\end{abstract}

\section{Introduction}

There is no doubt that regular sporting activity has physiological benefits, but there is no evidence that there are benefits of extreme endurance sports. Indeed, there are indications that ultra-distance runners, for example, may suffer increased health risks due to high oxidative stress, which generates aggressive oxygen radicals and metabolites that can damage cells and cell components [1-3].

Several interesting concepts have emerged from these types of experimental studies [3-10]. Regular physical exercise enhances the antioxidant defense system and protects against exercise-induced free radical damage. This is an important finding, because it shows how smart the body is about adapting to the demands of exercise. These changes occur slowly over time and appear to parallel other adaptations to exercise.

When exercising, the body is in an elevated aerobic metabolic state that increases the production of free radicals. That happens because the two primary fuel sources in the body, carbohydrates and fats, convert into energy through a process called oxidation. During oxidation, not all oxygen atoms bind with hydrogen, thus ending up as free radicals. Normally, the body wants to stay in an oxidative balance, with equal numbers of free radicals and antioxidants, which are free-radical inhibitors [10-12].

Running is one of the earliest and simplest types of aerobic activity. The combination of science and technology has led to the evolution of new forms of running. KJ boots are an example of a new innovative technology that is continuing the evolution of this age-old activity and is defined to be the newest way to getting rid of stress. These boots are designed to dissipate the impact stress and forces experienced through the ankles, knees, hips, and back by up to $80 \%$. Due to the reduced impact of running with the use of the KJ boots, it is also confirmed (by three distinct scientific studies) [1315] that subjects wearing running shoes will have a greater incidence of impact stress than those wearing KJ boots [13].

The question that arises is how subjects can effectively defend against the increased free radicals resulting from this innovative type of aerobics.

If we are considering a fitness or an exercise program, it is vital to understand the risks and the complications that may be associated with the program we are considering. 
While we commonly believe of injuries, including muscle strains and sprains, as the most significant health pain, there are physiological complications that may arise out of electrolyte imbalance and similar conditions. One such complication, known as oxidative stress, is quite common and often overlooked as a health risk with exercise and fitness programs.

Stress and obesity are the "diseases of the century" and we focus our paper's goal to this, by assessment, supervision, and interpretation of cellular damage. Because it is not possible to directly measure free radicals in the body, we approach this question by measuring the by-products (breath ethylene) that result from free radical reactions.

Ethylene from the human breath is an indicator of oxidant stress and can be directly correlated to physiological events in the patients (or biochemical events surrounding lipid peroxidation) [16].

Lipid peroxidation is the free-radical-induced oxidative degradation of polyunsaturated fatty acids, where biomembranes and cells are thereby disrupted, causing cell damage and cell death. The ultimate step in the peroxidative chain reaction is the formation of different hydrocarbons molecules, depending on the molecular arrangement of the fatty acid involved. In the human body, the fatty acids inside the membrane lipids are mainly linoleic acid and arachidonic acid. The peroxidation of these fatty acids produces two volatile alkanes, ethylene and pentane, respectively. Both of them are considered in the literature to be good biomarkers of free-radical-induced lipid peroxidation in humans [17]. The fact that ethylene is highly volatile, not significantly metabolized by the body, and not soluble in body fat means that it diffuses rapidly into bloodstream after generation and it is transported to the lungs. The membranes separating the air in the lungs from the blood in the capillaries are very thin and are optimized for gas transport, so ethylene is easily emitted in exhaled breath and then collected [18, 19]. This speeds noninvasive patient monitoring applications when an appropriately periodic and rigorous breath sampling regime is used.

The chain of processes involving any gaseous compound excreted with exhaled breath can be represented in the general form as follows: production of the biomarker during a particular biochemical reaction or a complex metabolic process; diffusion of biomarker through tissues and input into haematic flow; possible intermediate accumulation; possible trapping of biomarker by utilization and assimilation systems or natural chemical transformation; transport to the lungs; transmembrane diffusion to the air space of lungs; diffusion of biomarker and their mixing with inhaled air in the alveolar space of lungs; release of biomarker in the breathing air; collection of a breath sample and assessment of the biomarker in the breath sample [20].

The quest for noninvasive, real-time monitoring tools is a characteristic of the modern medicine. The technique that will be applied in this research complies with this requirement ensuring the advantages of health state assessment by monitoring the evolution of gaseous biomarkers in human body, impossible to achieve with current techniques. Our propose is to characterize by breath air analysis one prevention domain (fitness), but the method can be easily extended to other pathological issues.

According to these features, we show the potential of LPAS as a powerful system for trace gas detection with exhaled breath assessment applications, focusing the attention on the determination of ethylene contained in exhaled breath of women practicing an innovative training device: KJ.

\section{LPAS Experimental Setup}

LPAS is a sensitive technique for detection and monitoring of trace gases at very low concentrations. The $\mathrm{CO}_{2}$ laser is of special interest, as it ensures high output power in a wavelength region where more than 200 molecular gases of environmental concern for atmospheric, industrial, medical, military, and scientific spheres exhibit strong absorption bands. This laser can be only stepwise tuned when operated in $\mathrm{cw}$, and it is an ideal source to push the sensitivity of photoacoustic gas detection into the concentration range of part per billion by volume (ppbV) or even lower. Instruments based on LPAS method have nearly attained the theoretical noise equivalent absorption detectivity of $10^{-10} \mathrm{~cm}^{-1}$ in controlled laboratory conditions. This high sensitivity cannot be achieved in real detection conditions due to the coherent photoacoustic background signal and interfering absorption of normal atmospheric constituents.

The schematic diagram of the LPAS system is illustrated in Figure 1 and is described in [21-26] with details of the general setup especially our resonant PA cell, the formula for the response of the system, the line tunability of the frequency stabilized $\mathrm{CO}_{2}$ laser, the quality factor of the PA cell, and a list of protocols to obtain a minimum detectable concentration as low as possible.

The experimental setup consists of a home-built, linetunable, and frequency stabilized $\mathrm{CO}_{2}$ laser. This laser, emitting radiation in the $9.2-10.8 \mu \mathrm{m}$ region on 73 different vibrational-rotational lines, has a maximum power of $6.5 \mathrm{~W}$ on the $10 \mathrm{P}(20)$ line. The requirement for gases to be detected with this sensitive laser is that they should possess relatively high absorption strength and a characteristic absorption pattern in the wavelength range of the $\mathrm{CO}_{2}$ laser. For ethylene, the largest absorption is attained at $10 \mathrm{P}(14)$ line of the $\mathrm{CO}_{2}$ laser $(10.53 \mu \mathrm{m})$.

Our laser beam was modulated by a high quality, low vibration noise, and variable speed $(4-4000 \mathrm{~Hz})$ mechanical chopper model DigiRad C-980 or C-995 (30 aperture blade), operated at the appropriate resonant frequency of the cell $(564 \mathrm{~Hz})$.

We used a dual-phase, digital lock-in amplifier (Stanford Research Systems model SR 830) with the following characteristics: full scale sensitivity, $2 \mathrm{nV}-1 \mathrm{~V}$; input noise, $6 \mathrm{nV}$ (rms) $/ \sqrt{\mathrm{Hz}}$ at $1 \mathrm{kHz}$; dynamic reserve, greater than $100 \mathrm{~dB}$; frequency range, $1 \mathrm{mHz}-102 \mathrm{kHz}$; time constants, $10 \mu \mathrm{s}-30 \mathrm{~s}$, or up to $30000 \mathrm{~s}$.

PA cell has a total volume of approximately $1.0 \mathrm{dm}^{3}$ and it is made of stainless steel and Teflon to reduce the outgassing problems. The PA cell consists of an acoustic resonator 


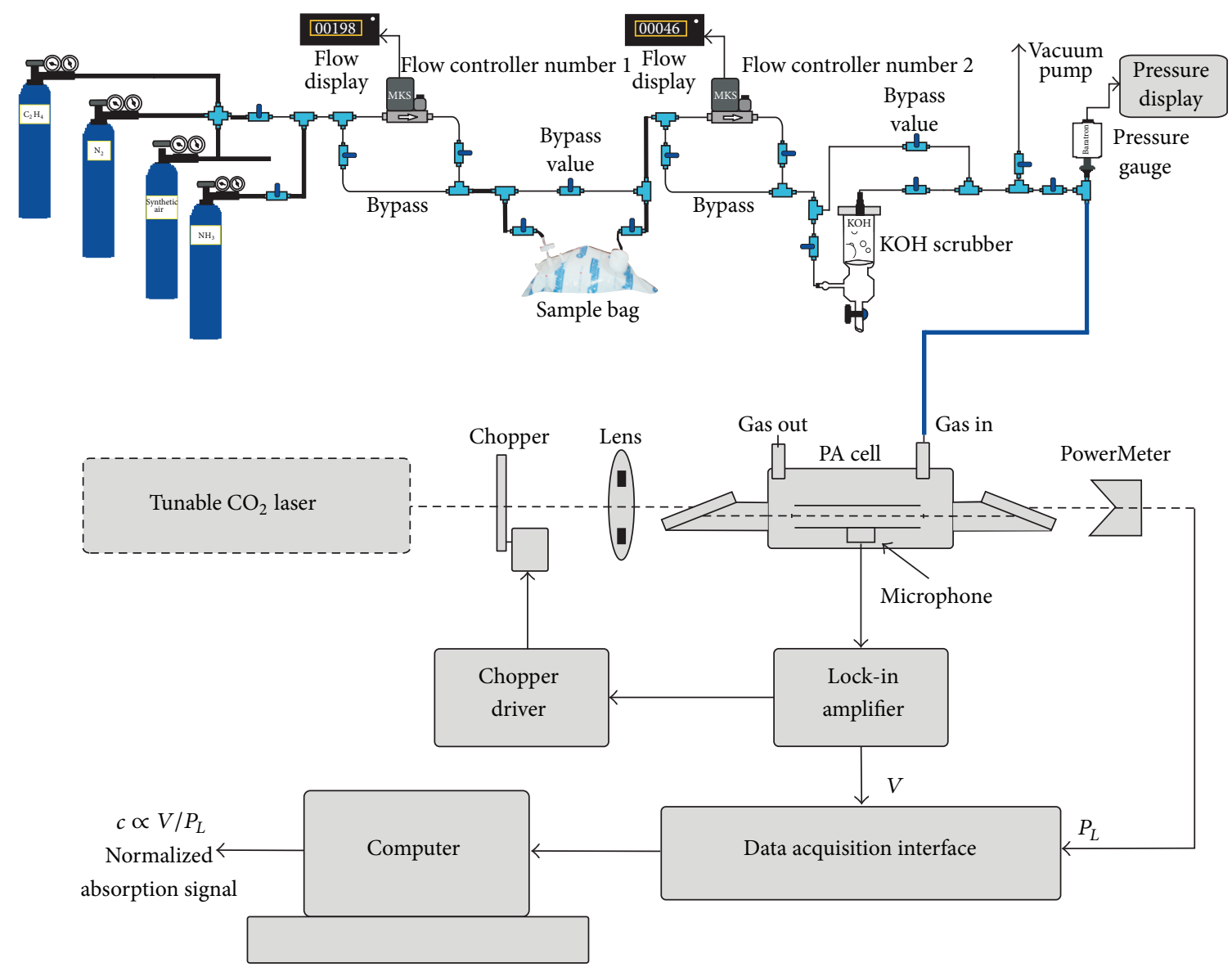

FIGURE 1: $\mathrm{CO}_{2}$ laser photoacoustic spectroscopy system.

tube, windows, gas inlets and outlets, and microphones and it contains an acoustic filter to suppress the window noise. The ZnSe windows are positioned at Brewster's angle to their mounts. The resonant conditions are obtained as longitudinal standing waves in an open tube (excited in its first longitudinal mode). To achieve a larger signal, we chose a long absorption path length-300 $\mathrm{mm}$ and an inner diameter of the pipe of $7 \mathrm{~mm}$. The fundamental longitudinal wave, therefore, has a nominal wavelength of $600 \mathrm{~mm}$ and a resonance frequency of $564 \mathrm{~Hz}$.

The two buffer volumes placed near the Brewster's windows have a length of $75 \mathrm{~mm}$ and a diameter of $57 \mathrm{~mm}$. The inner wall of the stainless steel resonator tube is highly polished. It is centered inside the outer stainless steel tube with Teflon spacers. A massive spacer is positioned at one end to prevent bypassing of gas in the flow system; the other is partially open to avoid the formation of closed volumes. Gas is admitted and exhausted through two ports located near the ends of the resonator tube. The perturbation of the acoustic resonator amplitude by the gas flow noise is thus minimized. The acoustic waves generated in the PA cell are detected by four Knowles electrets miniature microphones in series, mounted flush with the wall. They are situated at the loops of the standing wave pattern, at an angle of $90^{\circ}$ to one another. The electrical output from these microphones is summed and the signal is selectively amplified by the lock-in amplifier [26].

Comparing with the best value previously reported [27] in the literature (minimum detectable concentration$3,8 \mathrm{ppbV}$ (parts per billion by volume)), our PA system is one of the most sensitive instruments, having a responsivity of $405 \mathrm{cmV} / \mathrm{W}$ and being able to measure the minimum detectable concentration of $0.9 \mathrm{ppbV}$.

We used a modular software architecture (Keithley TestPoint software) that is aimed at controlling the experiments, collecting data, and preprocessing information. It helps to automate the process of collecting and processing the experimental results. The software transfers powerMeter readings, normalizes data, and automatically stores files. It allows the user to record parameters such as the PA cell responsivity (a constant used to normalize raw data), gas absorption coefficient, number of averaged samples at every measurement point, sample acquisition rate, and the total number of measurement points. This software interfaces the lock-in amplifier, the chopper, the laser powerMeter, and the gas flowmeter. It allows the user to set or read input data and instantaneous values for the PA voltage, average laser power after chopper, and trace gas concentration [26].

Of great significance in these determinations is the gas handling system due to its role in ensuring gas purity in 
the PA cell (the upper part of Figure 1). It can be used to pump out the cell, to introduce the sample gas in the PA cell at a controlled flow rate, and to monitor the total and partial pressures of gas mixtures. Also, the gas handling system can perform several functions without necessitating any disconnections $[25,26]$.

Women's exhaled breath samples were collected inside aluminized bags using a disposable mouth piece connected to the sample bags via homemade Teflon mouthpiece adaptor, and after collection, the sample gas is transferred into the measurement PA cell.

\section{Results and Discussions}

Ethylene breath biomarker was measured using the LPAS system, and volunteers were recruited from women participating in KJ exercise program (3 times per week, with a $1 \mathrm{~h} \mathrm{KJ}$ session) organized by the Prosper Fitness, Bucharest. KJ program implies one hour of a lot of new steps and great choreographies with music. The first 10 minutes of the program are dedicated to the initiation in the exercises and the last 10 minutes are dedicated to the body relaxation.

Experimental determinations in order to evaluate, interpret, and understand the by-product of oxidative stress were performed for five women with age between 23 and 30 years. The control women, considered healthy, were nonsmokers, nonalcoholic, and nondiabetic, without any chronical affection.

The tested women involved in the experiments did not take synthetic antioxidants before the beginning of the KJ program, and breath samples were collected at certain time intervals, before (with 5 minutes before the start of the exercises) and after the KJ program (immediately after the end of the exercises) with a normal exhalation flow rate.

An essential parameter is the responsivity $R(\mathrm{cmV} / \mathrm{W})$ of the PA cell which depends on the pressure of the gas inside the cell (Figure 2).

The initial pressure in the sample bags filled by the healthy women differs from one case to another, and it is necessary to know the pressure dependence of the PA cell responsivity. The exhaled air sample was transferred to the PA cell at a controlled flow rate of $36 \mathrm{~L} / \mathrm{h}(600 \mathrm{sccm}$ : standard cubic centimeters per minute), and the total pressure of the gas in the cell was measured, applying then the correction factor for the responsivity according to the calibration curve from Figure 2. The responsivity of the PA cell was determined for ethylene at $10 \mathrm{P}(14) \mathrm{CO}_{2}$ laser line by using a calibrated mixture (Linde Gas) of $9.88 \mathrm{ppmV}( \pm 2 \%) \mathrm{C}_{2} \mathrm{H}_{4}$ diluted in nitrogen 6.0 (purity 99.9999\%) and verified with another calibrated mixture of $0.96 \mathrm{ppmV}( \pm 5 \%) \mathrm{C}_{2} \mathrm{H}_{4}$ diluted in nitrogen 5.0 (purity 99.999\%) [26].

The absorption coefficients of ethylene at different $\mathrm{CO}_{2}$ laser wavelengths were precisely measured previously $[25$, 26].

During the transfer of the exhaled air from the collecting bag to the PA cell, the sample gas was passed through a trap filled with $\mathrm{KOH}$ pellets to remove the $\mathrm{CO}_{2}$ and $\mathrm{H}_{2} \mathrm{O}$ vapors. The signal decreased considerably when a trap with

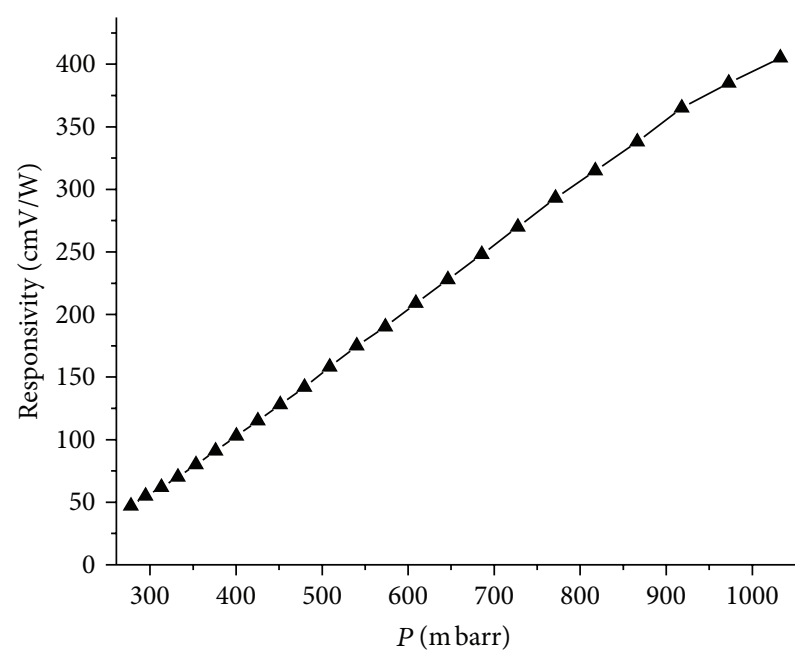

FIgURE 2: The responsivity of the PA cell against the pressure.

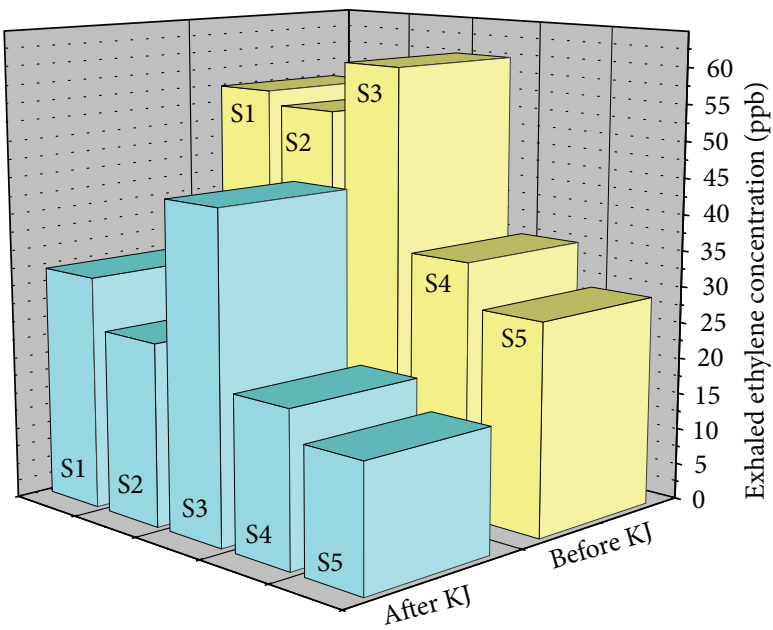

FIGURE 3: The by-product of oxidative stress at five women (S1-S5) practicing the innovative $\mathrm{KJ}$ training.

a volume larger than $100 \mathrm{~cm}^{3}$ was inserted [28], showing that the existing amounts of $\mathrm{CO}_{2}$ and $\mathrm{H}_{2} \mathrm{O}$ vapors in the breath can significantly alter the results; thus their removal is being compulsory.

Experimental determinations of breath ethylene for women (S1-S5) were performed and the results are presented in Figure 3. All determinations were made at $10 \mathrm{P}(14) \mathrm{CO}_{2}$ laser line (absorption coefficient: $30.4 \mathrm{~cm}^{-1} \mathrm{~atm}^{-1}$ ).

In Figure 3, we have measured the by-product of the oxidative stress during $\mathrm{KJ}$ program in five womens using the exhaled ethylene as a biomarker and LPAS system as a method of detection. As shown in the figure, we can observe that the level of ethylene breath biomarker after the $\mathrm{KJ}$ program is decreased compared to the ethylene breath biomarker concentration before the start of KJ exercise program (between $47 \%$ and $74 \%$, average $60 \%$ ). It can be hypothesized that subjects who make KJ exercise would have a lower incidence of damage at membrane cell level and this 
innovative exercise program can protect cells from oxidative damage and stress, reducing the generation of prooxidants during and after the exercise.

The term oxidative stress refers to a serious imbalance between production of reactive oxygen species and antioxidant defence in favour of the oxidants, potentially initiators of cellular damage.

The decreased level of ethylene appears because of the significant reduction of impact force during KJ exercises, inside the volunteers organism producing only "good" free radicals followed by a low concentration of oxidative stress.

As secondary messenger of part of the immune system defence the low level of oxidative stress has many important physiological functions while moderate and high levels of oxidative stress (or the production of "bad" free radicals) within cells may lead to membrane cell damage and DNA lesions.

\section{Conclusions}

Determinations from this preliminary evaluation of breath test during $\mathrm{KJ}$ exercise suggest that the $\mathrm{KJ}$ may reduce the oxidative stress, and LPAS system provides a useful evaluation of ethylene biomarker (as a by-product of oxidative stress occurring inside the cells), being perfectly suitable to assessing the breath gases.

This is the first attempt in the literature which has investigated the use of $\mathrm{KJ}$ for the risks of oxidative stress capacity.

High sensitivity and selectivity, immune to interference, high accuracy and precision, minor sample preparation, good temporal resolution, ease of use, versatility, reliability, robustness, and a relatively low cost per unit make LPAS technique functional in a large dynamic range for measurement of trace gases.

As for future work, more research is needed to investigate the use of KJ boots for the risk of oxidative stress capacity by keeping the present determinations as reference and the exhaled ethylene as a specific by-product of oxidative stress (with a larger number of volunteers).

\section{Acknowledgments}

The authors wish to thank Ms. Alexandra Dragomir (KJ international instructor at Prosper Fitness) for clinical cooperation and the Romanian National Authority for Scientific Research, CNCS-UEFISCDI, Project no. PN-II-RU-TE-20113-0269 (TE 50).

\section{References}

[1] B. Poljsak, I. Milisav, T. Lampe, and I. Ostan, "Reproductive benefit of oxidative damage: an oxidative stress "malevolence"?" Oxidative Medicine and Cellular Longevity, vol. 2011, Article ID 760978, 9 pages, 2011.

[2] U. K. Senturk, F. Gunduz, O. Kuru et al., "Exercise-induced oxidative stress leads hemolysis in sedentary but not trained humans," Journal of Applied Physiology, vol. 99, no. 4, pp. 14341441, 2005.
[3] Austrian Science Fund FWF, http://www.fwf.ac.at/en/public relations/press/pv200808-2en.html.

[4] J. E. Tauton, N. S. Miller, E. C. Rhodes, B. D. Zumbo, and S. Fraser, "Kangoo Jumps-University of BC-Canada," Max VO2 Improvements \& Injury Prevention, vol. 1, 2002.

[5] http://kangooclubsouthbay.com/12-weeks.html.

[6] R. J. Bloomer and A. H. Goldfarb, "Anaerobic exercise and oxidative stress: a review," Canadian Journal of Applied Physiology, vol. 29, no. 3, pp. 245-263, 2004.

[7] A. M. Jones and H. Carter, "The effect of endurance training on parameters of aerobic fitness," Sports Medicine, vol. 29, no. 6, pp. 373-386, 2000.

[8] R. A. Robergs and S. O. Roberts, Exercise Physiology, Mosby, St. Louis, Mo, USA, 1997.

[9] "American College of Sports Medicine Position Stand: the recommended quantity and quality of exercise for developing and maintaining cardiorespiratory and muscular fitness in healthy adults," Medicine \& Science in Sports \& Exercise, vol. 22, pp. 265-274, 1990.

[10] C. A. Macera, R. R. Pate, K. E. Powell, K. L. Jackson, J. S. Kendrick, and T. E. Craven, "Predicting lower-extremity injuries among habitual runners," Archives of Internal Medicine, vol. 149, no. 11, pp. 2565-2568, 1989.

[11] M. L. Urso and P. M. Clarkson, "Oxidative stress, exercise, and antioxidant supplementation," Toxicology, vol. 189, no. 1-2, pp. 41-54, 2003.

[12] A. Taylor and M. Johnson, Physiology of Exercise and Healthy Aging, Human Kinetics, 2008.

[13] N. Miller, J. E. Taunton, S. Fraser, E. Rhodes, and B. Zumbo, "Kangoo Jumps: an innovative training device," British Columbia Medical Journal, vol. 45, no. 9, pp. 444-448, 2003.

[14] R. U. Newton, B. J. Humphries, and I. B. Ward, "Reducing ground impact forces during jogging: an evaluation of shoes with springs," Unpublished data, 1995.

[15] T. S. Keller, A. M. Weisberger, J. L. Ray et al., "Relationship between vertical ground reaction force and speed during walking, slow jogging, and running," Clinical Biomechanics, vol. 11 , no. 5, pp. 253-259, 1996.

[16] G. J. Handelman, "Current studies on oxidant stress in dialysis," Blood Purification, vol. 21, no. 1, pp. 46-50, 2003.

[17] G. Giubileo, "Laser based assessment of lipid peroxidation in humans," in ROMOPTO '97: 5th Conference on Optics, vol. 3405 of Proceedings of SPIE, pp. 642-653, September 1998.

[18] K. S. Stevenson, K. Radhakrishnan, C. S. Patterson et al., "Breath ethane peaks during a single haemodialysis session and is associated with time on dialysis," Journal of Breath Research, vol. 2, no. 2, Article ID 026004, 8 pages, 2008.

[19] O. Dale, H. Bergum, T. Lund, T. Nilsen, P. Aadahl, and R. Stenseth, "A validated method for rapid analysis of ethane in breath and its application in kinetic studies in human volunteers," Free Radical Research, vol. 37, no. 8, pp. 815-821, 2003.

[20] G. Giubileo, "Medical diagnostics by laser-based analysis of exhaled breath," in ALT'01 International Conference on Advanced Laser Technologies, vol. 4762 of Proceedings of SPIE, 2002.

[21] D. C. Dumitras, D. C. Dutu, C. Matei et al., "Measurements of ethylene concentration by laser photoacoustic techniques with applications at breath analysis," Romanian Reports on Physics, vol. 60 , no. 3, pp. 593-602, 2008. 
[22] D. C. Dumitras, D. C. Dutu, C. Matei, A. M. Magureanu, M. Petrus, and C. Popa, "Improvement of a laser photoacoustic instrument for trace gas detection," UPB Scientific Bulletin, Series A, vol. 69, no. 3, pp. 45-56, 2007.

[23] D. C. Dumitras, S. Banita, A. M. Bratu et al., "Ultrasensitive $\mathrm{CO}_{2}$ laser photoacoustic system," Infrared Physics and Technology, vol. 53, no. 5, pp. 308-314, 2010.

[24] C. Popa, A. M. Bratu, C. Matei, R. Cernat, A. Popescu, and D. C. Dumitras, "Qualitative and quantitative determination of human biomarkers by laser photoacoustic spectroscopy methods," Laser Physics, vol. 21, no. 7, pp. 1336-1342, 2011.

[25] D. C. Dumitras, D. C. Dutu, C. Matei et al., "Evaluation of ammonia absorption coefficients by photoacoustic spectroscopy for detection of ammonia levels in human breath," Laser Physics, vol. 21, no. 4, pp. 796-800, 2011.

[26] D. C. Dumitras, D. C. Dutu, C. Matei, A. M. Magureanu, M. Petrus, and C. Popa, "Laser photoacoustic spectroscopy: principles, instrumentation, and characterization," Journal of Optoelectronics and Advanced Materials, vol. 9, no. 12, pp. 36553701, 2007.

[27] F. J. M. Harren, F. G. C. Bijnen, J. Reuss, L. A. C. J. Voesenek, and C. W. P. M. Blom, "Sensitive intracavity photoacoustic measurements with a $\mathrm{CO}_{2}$ waveguide laser," Applied Physics B, vol. 50, no. 2, pp. 137-144, 1990.

[28] A. M. Bratu, C. Popa, C. Matei, S. Banita, D. C. A. Dutu, and D. C. Dumitras, "Removal of interfering gases in breath biomarker measurements," Journal of Optoelectronics and Advanced Materials, vol. 13, no. 8, pp. 1045-1050, 2011. 

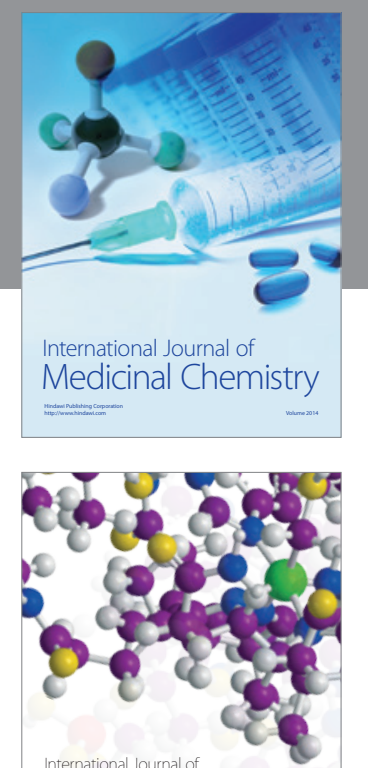

\section{Carbohydrate} Chemistry

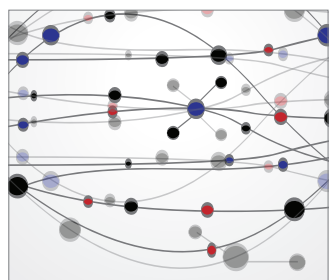

The Scientific World Journal
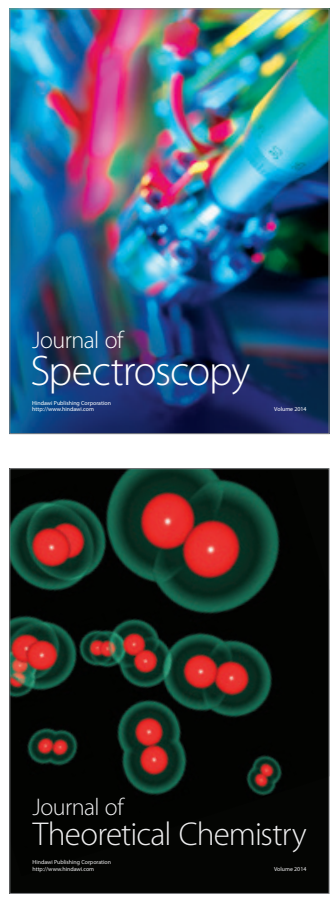
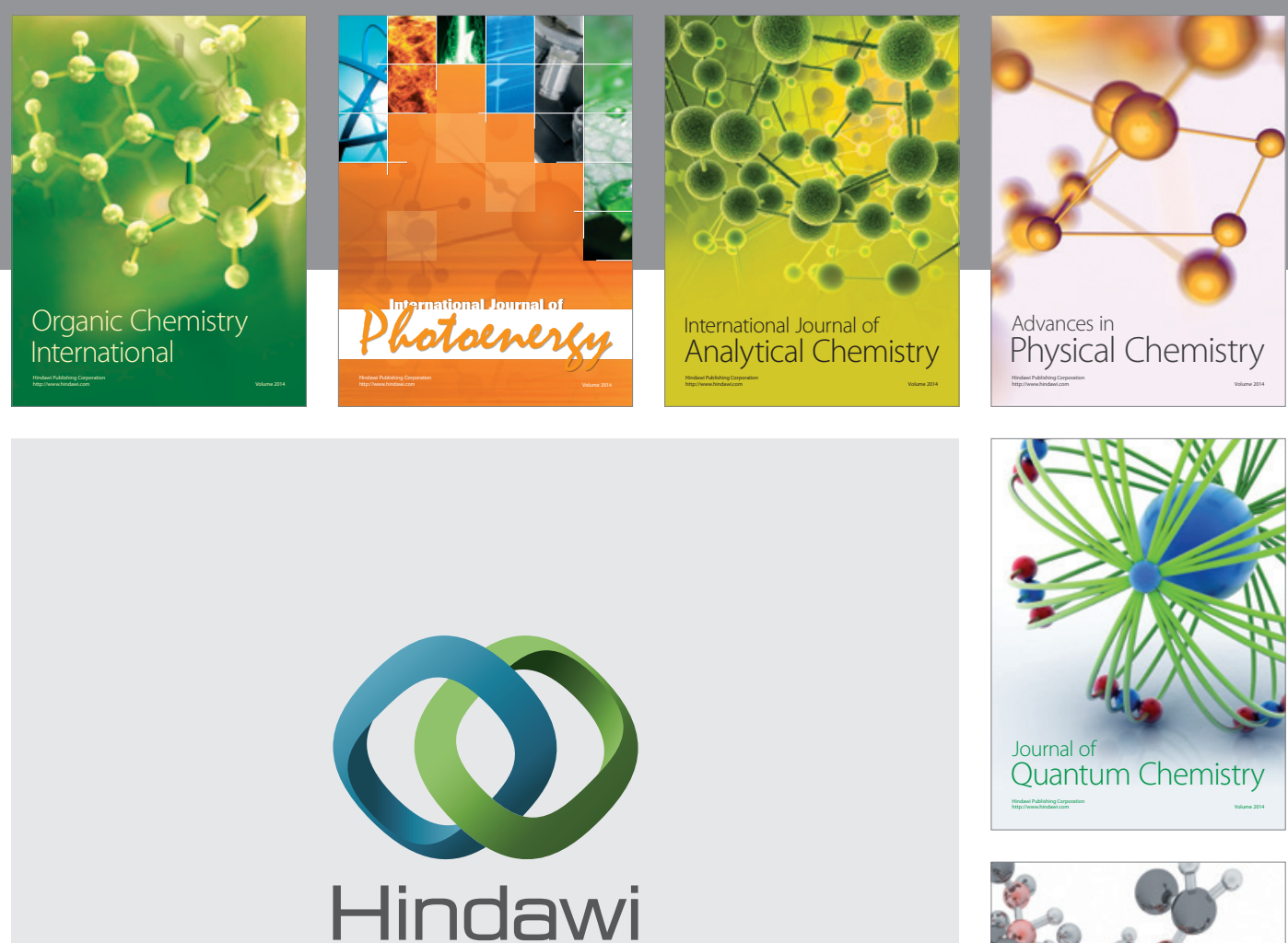

Submit your manuscripts at

http://www.hindawi.com

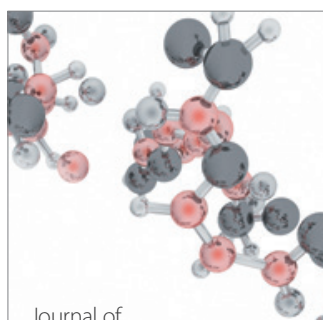

Analytical Methods

in Chemistry

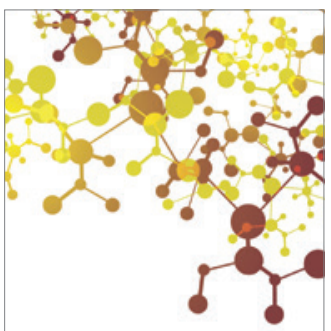

Journal of

Applied Chemistry

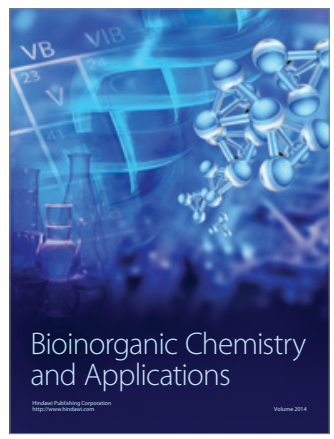

Inorganic Chemistry
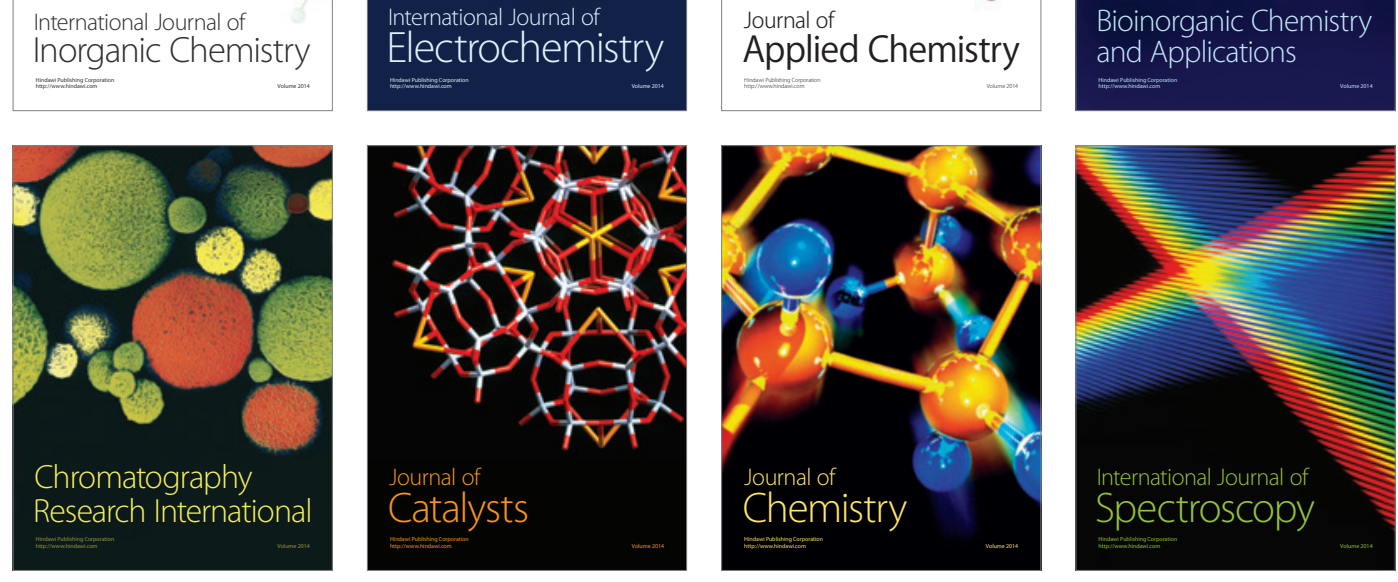